\title{
Paradoxical embolism associated with patent foramen ovale
}

\author{
R. C. F. LEONARD* \\ M.D., M.R.C.P.
}

\author{
E. NeVILLE* \\ M.D., M.R.C.P.
}

\author{
R. J. C. Hall $\dagger$ \\ M.D., M.R.C.P. \\ Departments of Medicine* and Cardiology†, \\ Royal Victoria Infirmary, Newcastle upon Tyne
}

\begin{abstract}
Summary
Two patients are described in whom paradoxical embolism was diagnosed during life. One patient with cerebral embolism died and the other, with peripheral embolization, survived after treatment with streptokinase. Thrombolytic therapy has not previously been described in the treatment of patients with paradoxical embolism.
\end{abstract}

\section{Introductio.1}

Paradoxical embolism is generally regarded as a rare event but the 2 cases described presented to a single unit within 6 months. This supports the view of Meister et al. (1972) that paradoxical embolism may be far more common than is frequently thought. The second case demonstrates the value of a high index of suspicion in making a clinical diagnosis so that appropriate and early treatment may be instituted.

\section{Case reports}

\section{Case 1}

A 43-year-old woman had a sigmoid colectomy for a localized carcinoma of the colon. One day postoperatively she collapsed and was found to be centrally cyanosed with a systolic BP of $80 \mathrm{mmHg}$ and a pulse of $130 / \mathrm{min}$. There was a loud gallop rhythm and an elevated jugular venous pressure. The ECG showed an $S_{1}, Q_{3}, T_{3}$ pattern and she was stuporose. The level of consciousness deteriorated and a right hemiparesis was noted. Emergency right heart catheterization and pulmonary angiography confirmed massive pulmonary embolism. Heparin was started but, despite a complete regression of her abnormal cardiovascular signs, the level of consciousness continued to deteriorate. She died 3 days later without regaining consciousness. Post-mortem examination showed a large left cerebral infarction with a blood clot hanging through a patent foramen ovale. The lungs were congested with partly obstructed pulmonary arteries.

\section{Case 2}

The second patient was a 46-year-old woman who had a hysterectomy for fibroids. Three days postoperatively she experienced the sudden onset of dyspnnea which progressed over the next week. On the day of her re-admission to hospital, she suddenly developed numbness and coldness of the lower limbs associated with tingling and weakness, which immediately followed a bout of coughing. On admission to hospital she was pale and dyspnoeic with a pulse of $120 / \mathrm{min}$ and a BP of $190 / 90 \mathrm{mmHg}$. The JVP was elevated and there was a gallop rhythm but no murmurs. Pulses were absent from the middle of the abdomen downwards and the legs were cold. The ECG showed $S_{1}, Q_{3}, T_{3}$ changes and the blood gases $\mathrm{Po}_{2}$ of $8.1 \mathrm{kPa}(62.3 \mathrm{mmHg})$ $\mathrm{PCO}_{2}$ of $3.4 \mathrm{kPa}(26.2 \mathrm{mmHg})$ and $\mathrm{pH}$ of $7.52 \mathrm{on}$ $28 \%$ oxygen. The chest X-ray was normal. Pulmonary embolism and paradoxical embolism of her lower abdominal aorta were diagnosed and she was treated with streptokinase. Within $24 \mathrm{hr}$ her dyspnoea lessened and the lower limb pulses reappeared. Cardiac catheterization carried out 3 months later confirmed the presence of a patent foramen ovale.

\section{Discussion}

Post-mortem evidence (Thompson and Evans, 1930 ) suggests that up to $6 \%$ of the population may have a sufficiently large foramen ovale to transmit a paradoxical embolus. Both of these patients confirm the association, evident from previously reported cases (Thompson and Evans, 1930; Padula and Camishion, 1968; Meister et al., 1972; Cheng, 1976; Laughlin and Mandal, 1977), between pulmonary embolism and paradoxical embolization when the cardiac lesion is a patent foramen ovale. 
This association is probably due to increased right atrial pressure secondary to pulmonary embolism which leads to opening of the patent foramen ovale.

Some of those earlier reports (Meister et al., 1972; Cheng, 1976; Laughlin and Mandal, 1977) suggest that the treatment of paradoxical embolism should be immediate ligation or plication of the inferior vena cava to prevent further emboli. However, this recommendation has always been based on small series of patients with marked heterogeneity and has never been compared with medical treatment within the same series. Caval interruption is theoretically attractive but in a series of patients with pulmonary embolism who were treated in this fashion there was a $4 \%$ perioperative mortality with a $2.6 \%$ incidence of recurrent pulmonary embolism (Nabseth and Moran, 1965). This compares with a $2.3 \%$ mortality from recurrent pulmonary embolism in a series of 126 patients, reported in 2 papers (Hall, Sutton and Kerr. 1977; Sutton, Hall and Kerr, 1977), who were treated with streptokinase, heparin or pulmonary embolectomy with subsequent warfarin. If patients survive the acute event of pulmonary embolism, their chance of long-term survival diminishes markedly in the presence of pre-existing cardio-respiratory disease (Moran, Criscitiello and Callow, 1969; Paraskos et al., 1973) irrespective of the initial form of treatment.

The use of streptokinase in peripheral paradoxical embolism is logical in attempting to lyse clot in deep veins, pulmonary artery and aorta but has not been previously described. However, such peripheral embolization is unusual and paradoxical embolism more commonly affects the cerebral vessels (Laughlin and Mandal, 1977). In this situation, streptokinase might be dangerous with an increased risk of haemorrhage into the infarcted cerebrum.

Anticoagulation of patients with cerebral embolism has been much debated, but the use of heparin and warfarin is thought to be safe so long as routine precautions are taken (Marshall, 1976). In a recent review (Easton and Sherman, 1980), it was suggested that any patient with a cerebral embolism from a cardiac source should be anticoagulated immediately provided that there was no blood in the CSF or haematoma on CT brain scan. Patients with paradoxical embolism suffer the same risks as those with a cardiac source of embolization and in both groups recurrent embolism is a major problem.

Accordingly, the management of all patients with paradoxical embolism should include immediate anticoagulation with heparin and subsequent oral anticoagulation. The use of thrombolytic therapy may be useful in the very occasional patient in whom major systemic arteries are obstructed but in whom there is no evidence of cerebral embolism. The value of various interruption operations, which in themselves may carry a significant mortality and morbidity remains unproved.

\section{References}

Cheng, T.O. (1976) Paradoxical embolism: a diagnostic challenge and its detection during life. Circulation, 53, 565.

Easton, J.D. \& Sherman, D.G. (1980) Cerebral embolism of cardiac origin. Stroke, 2, 433.

Hall, R.J.C., Sutton, G.C. \& KerR, I.H. (1977) Longterm prognosis of treated acute massive pulmonary embolism. British Heart Journal, 39, 1128.

LAUGhliN, R.A. \& MANDAL, S.R. (1977) Paradoxical embolisation. Archives of Surgery, 112, 648.

Marshall, J. (1976) The Management of Cerebrovasculas Disease, 3rd edn, p. 112. Blackwell Scientific Publications Oxford.

Meister, S.G., Grossman, W., Dexter, I. \& Dalen, J.E (1972) Paradoxical embolism: diagnosis during lifeAmerican Journal of Medicine, 153, 292.

Moran, J.M., Criscitiello, M.G. \& Callow, A.D. (1969) Vena cava interruption for thrombo-embolism: partial or complete? Influence of cardiac disease upon results. Circulation, 39 (suppl. 1), 263.

NABSETH, D.C. \& Moran, J.M. (1965) Reassessment of the role of inferior vena cava ligation in venous thrombo- $\overrightarrow{\vec{D}}$ embolism. New England Journal of Medicine, 273, 1250.

PAdula, R.T. \& CAMISHION, R.C. (1968) Paradoxical embolisation. Annals of Surgery, 167, 598.

Paraskos, J.A., Adelstein, S.J., SMith, R.E., Rickman, F.D., Grossman, W., Dexter, L. \& Dalen, J.E. (1973) خ Late prognosis of acute pulmonary embolism. New England Journal of Medicine, 289, 55.

Sutton, G.C., Hall, R.J.C. \& KerR, I.H. (1977) Clinical course and late prognosis of treated subacute massive, acute minor, and chronic pulmonary thrombo-embolism. British Heart Journal, 39, 1135.

Thompson, T. \& Evans, W. (1930) Paradoxical embolism Quarterly Journal of Medicine, 23, 135. 